\title{
Serum alanine transaminase (ALT) reference ranges estimated from blood donors
}

\author{
D J Goldie, A A McConnell
}

\begin{abstract}
It has been suggested that an increase in serum alanine transaminase (ALT) activity in blood donors may identify infection with non- $A$, non-B hepatitis. To facilitate identification of such donors, the reference range for ALT was measured on a Technicon SMAC 1 Analyser, using serum from 364 blood donors and 567 plasmapheresis donors. The distribution of ALT activities displayed a positive skewness, and so both logarithmic transformation and subsequent calculation of mean and standard deviation as well as non-parametric analysis were used to obtain best estimates of reference ranges for men and women, 5-65 IU/1 and 5-35 IU/1, respectively. ALT activities were found to be higher in plasmapheresis donors than in normal blood donors of both sexes, and it is postulated that this difference may be related to the increased frequency of donation in the former group.
\end{abstract}

Post-transfusion hepatitis is usually due to the non-A, non-B (NANB) viruses, for which there is no test routinely used for screening in the United Kingdom. Most of these cases of non-A, non-B hepatitis following transfusions are now thought to be due to hepatitis $C$ for which an antibody screening test has recently become available, ${ }^{1}$ although none was available at the time of this study. Observations in haemophilic patients indicate that NANB infection may often be subicteric, presenting as an influenza-like illness, with disordered liver function tests. ${ }^{2}$ The incidence of posttransfusion hepatitis due to NANB viruses is unknown but is thought to be of the order of $90 \%$ of all post-transfusion hepatitis cases in the United States. ${ }^{2}$ It has been suggested that screening with liver function tests, especially of alanine transaminase activity, may identify a proportion of infective donors. ${ }^{3}$ Furthermore, it has been reported that the higher the increase of ALT in donor blood, the higher the risk of the donor being a carrier. ${ }^{45}$ In assessing the normality of ALT activity the difference in the reference range between the sexes must be recognised. ${ }^{67}$ If ALT is to be used to identify infected donors it is of course essential that reference ranges should be defined with as much confidence as possible; consequently it was decided to assess the reference range for our current ALT method (Technicon method number SG4-0079M84).

\section{Methods}

Blood samples from 364 blood donors and from 567 plasmapheresis donors, bled between 1985 and 1987, were randomly selected and analysed on the next routine assay for ALT. Any sample which was haemolysed or unseparated overnight was discarded, and samples were stored at $4^{\circ} \mathrm{C}$ until assay. Both groups of samples were handled in an identical manner. The age and sex of each donor were recorded. The ALT estimations were carried out on a Technicon SMAC 1 analyser at $37^{\circ} \mathrm{C}$. The possibility of following up patients who had received specific identifiable donations of blood or plasmapheresis products was rejected as impractical because transfusion usually involved several donors and the difficulty of matching donors and recipients across a large region would be formidable.

\section{Results}

The distribution of ALT activities found (figure) displayed a positive skewness similar to that reported by Mijovic et al. ${ }^{7}$ A total of five results which were manifestly abnormal (greater than $90 \mathrm{IU} / 1$ ) were excluded. Because the distributions were non-normal, a logarithmic transformation was performed to attempt to achieve an approximately normal distribution from which the mean and standard deviation were calculated. Anti-logarithmic transformation of the mean, mean $+2 \mathrm{SD}$, and mean - 2 SD were carried out to give the results tabulated overleaf. Non-parametric estimation of the $2 \cdot 5$ th and 97.5 th centiles was also done. The results are shown in the table: higher ALT activities were found in plasmapheresis donors of both sexes than in whole blood donors. Unpaired $t$ testing, however, showed this difference to be significant only in the two male groups $(0.001<\mathrm{p}<0.01)$. 

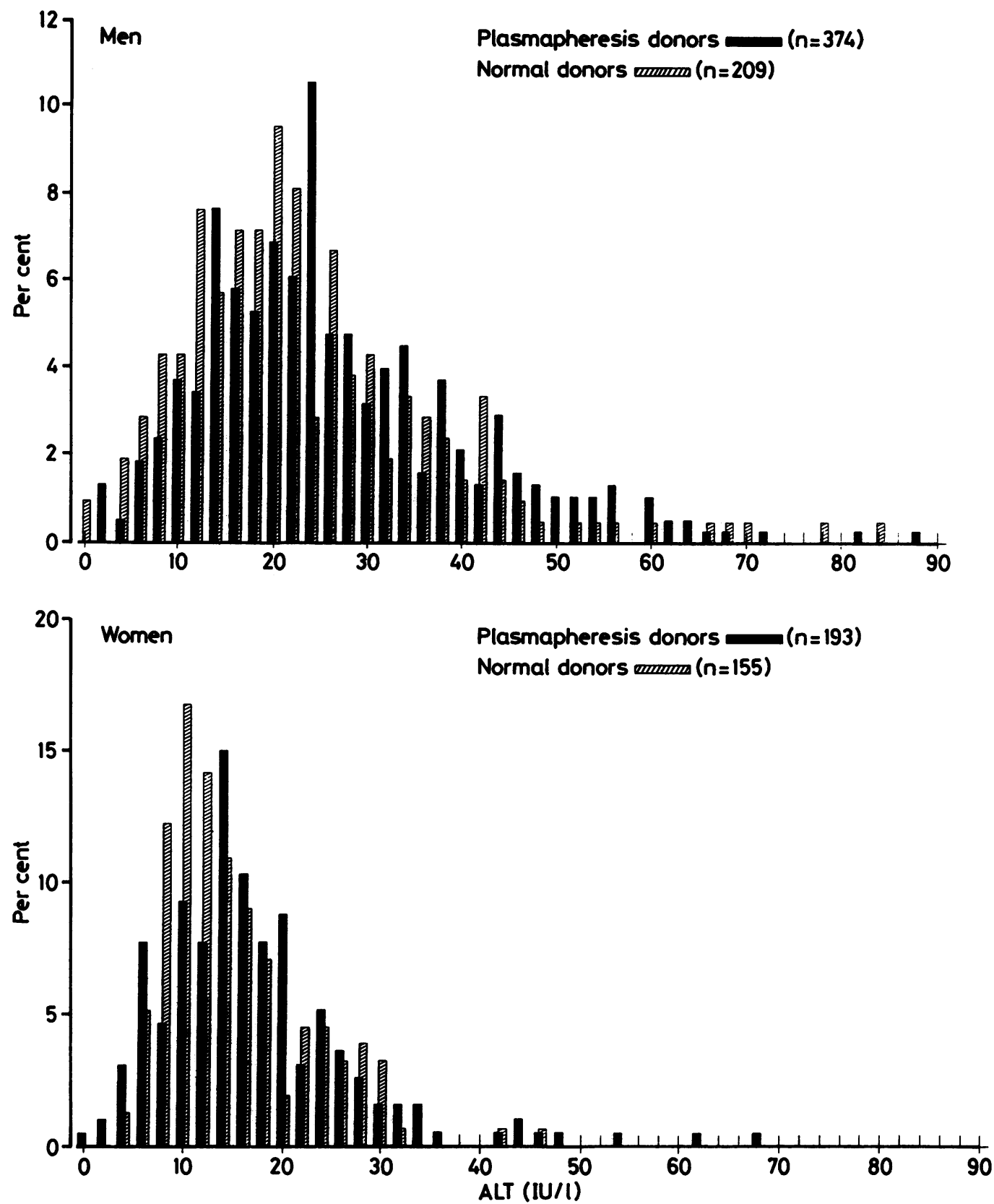

Distribution of ALT activities in normal and plasmapheresis donors.

Estimates of reference ranges for $A L T$ (IU)

\begin{tabular}{|c|c|c|c|c|c|c|}
\hline & Mean & $\begin{array}{l}\text { Mean } \\
-2 S D\end{array}$ & $\begin{array}{l}\text { Mean } \\
+2 S D\end{array}$ & Median & Mode & $\begin{array}{l}2 \cdot 5 \text { th-97.5th } \\
\text { centile } \\
\text { range }\end{array}$ \\
\hline $\begin{array}{l}\text { Male blood donors }(n=209) \\
\text { Male plasmapheresis donors }(n=374) \\
\text { Female blood donors }(n=155) \\
\text { Female plasmapheresis donors }(n=193)\end{array}$ & $\begin{array}{l}20 \cdot 1 \\
23 \cdot 4 \\
14 \cdot 1 \\
15 \cdot 2\end{array}$ & $\begin{array}{l}6 \\
7 \\
6 \\
5\end{array}$ & $\begin{array}{l}72 \\
75 \\
35 \\
48\end{array}$ & $\begin{array}{l}20 \\
25 \\
13 \\
16\end{array}$ & $\begin{array}{l}20 \\
25 \\
11 \\
15\end{array}$ & $\begin{array}{l}6-64 \\
5-62 \\
5-32 \\
5-46\end{array}$ \\
\hline
\end{tabular}

\section{Discussion}

The reference ranges derived from the two different procedures yielded different results, and under these circumstances the best estimates are expected to be derived by nonparametric means. It is suggested, therefore, that reference ranges of 5-65 IU/1 for men and 5-35 IU/1 for women may be regarded as appropriate. These ranges differ from the upper limits reported recently by Mijovic et al (52.4 IU/1 for men and $30.3 \mathrm{IU} / 1$ for women). The reason for these differences is unclear but may be related to methodological differences in that the analyses reported by Mijovic et al were performed on an EPOS analyser.

The higher ALT activities found in plasmapheresis donors of both sexes is interesting and may be related to the fact that plasmapheresis donors donate considerably more frequently than blood donors (about once every four weeks as opposed to twice yearly). This more frequent depletion of plasma protein might be expected to cause an increased flux of protein from hepatic paren- 
chymal cells which may be associated with excessive loss of ALT into the circulation.

An alternative explanation might have been associated with age differences between the two donor groups as it has been reported that ALT values (in men) peak at age 34 years. ${ }^{8}$ In this study, however, the mean and median ages of the two male groups were virtually identical (normal donors mean 34 years, median 31 years; plasmapheresis donors mean 33 years, median 30 years).

The cooperation of the Director and staff of the South Western Regional Transfusion Centre in making this study is gratefully acknowledged.

1 Underwood JCE. Hepatitis C virus and transfusion transmitted liver disease: Review. J Clin Pathol 1990;43:445-7.
2 Jones PM. Blood donors with a history of jaundice. $\mathrm{Br} \mathrm{Med} \mathrm{J}$ 1982;285:834.

3 Aach RD, Kahn RA. Post-transfusion hepatitis: current perspectives. Ann Intern Med 1980;92:539-46.

4 Thomas HC. Non-A, non-B hepatitis. $Q J$ Med 1987; 65:793-8.

5 Hollinger FB, Mosley JW, Szmuness W, et al. Non-A, non$B$ hepatitis following blood transfusion: Risk factors associated with donor characteristics. In: Szmuness W, Alter HJ, Maynard JE, eds. Viral hepatitis. Philadelphia: Franklin Institute Press, 1982:361-76.

6 Henry JR, Chianori N, Golub OJ, Berkman S. Revised spectrophotometric methods for the determination of glutamic-oxaloacetic transaminase, glutamic-pyruvic transaminase and lactic acid dehydrogenase. Am J Clin Pathol 1960;34:381.

7 Mijovic V, Contreras M, Barbara JAJ. Serum alanine amino-transferase (ALT) and gamma-glutamyl transferase (gamma GT) activities in north London blood ferase (gamma GT) activities in north
donors. J Clin Pathol 1987;40:1340-4.

8 Robinson D, Whitehead TP. Effect of body mass and other factors on serum liver enzyme levels in men attending for well population screening. Ann Clin Biochem 1989; 26:393-400. 